\title{
Institutional Factors Affecting Maternal Mortality in a Teaching Hospital
}

\author{
HA BABYa, DR SHAHA ${ }^{b}$
}

\begin{abstract}
Summary:
Objective: To identify the institutional factors causing third delay of maternal mortality in Faridpur Medical College Hospital- a tertiary public health care centre in Bangladesh.

Design: Cross-Sectional Study.

Study period: January 2001 to December 2005.

Methods and Materials: The case notes of all maternal deaths were reviewed at the end of each month during the study period. Various factors causing delay in the proper management of the cases were identified and noted. The data obtained from these reviews formed the basis of this study.

Results: During the study period total 202 mothers died giving the maternal mortality 2010.5 per 100,000 deliveries. In 130(64.4\%) cases one or more institutional factors were identified those contributed significantly to maternal deaths. The identified factors were: delayed
\end{abstract}

Introduction:

Maternal mortality is a major public health problem in developing countries like Bangladesh. Of the estimated total 536000 maternal death worldwide in 2005 , developing countries accounted for $99 \%$ of these deaths and in Bangladesh the number was $21000 .{ }^{1}$

A systematic review showed hemorrhage, hypertensive disorders, abortion, sepsis and obstructed labor are the major causes of maternal death world wide. ${ }^{2}$

The major causes of maternal mortality in Bangladesh are hemorrhage, eclampsia, sepsis, induced abortions, and obstructed labor. 3, 4, 5, 6 .

a. Dr. Hosne Ara Baby, FCPS (Obs \& Gyne), Professor (Obstetrics \& Gynecology), Enam Medical College, Savar.

b. Dr. Dipti Rani Shaha, FCPS (Obs \& Gyne), Junior Consultant (Obstetrics \& Gynecology), Faridpur Medical College Hospital. Faridpur

Address of Correspondence: Dr. Hosne Ara Baby, 'Alindo' Apartment, Flat No- 102, House No- 88, Road No- 8/A (New), Dhanmondi, Dhaka- 1209.

Received: 18 December, 2007

Accepted: 29 October, 2009 blood transfusion or non availability of blood (40\%); delayed or lack of operative interventions (37\%); late or nonattendance by senior doctors (24.8\%); operative interventions done by junior doctors (9.9\%); non availability of ICU (intensive care unit) facility (29.7\%) and of medicine (7.4\%).

Conclusion: There is a steady fall in maternal mortality ratio (MMR) in Bangladesh since 1990. But to reach the Millennium Development Goal for maternal health (MDG-5), the MMR will need to decrease at a much faster rate in the future. Improvement of the infrastructural facilities in the hospital can help to remove the preventable institutional factors causing third delay of maternal mortality. This can be a short term strategy to reduce maternal mortality

Key words: Maternal mortality, Institutional factor, Third delay.

(J Bangladesh Coll Phys Surg 2010; 28: 5-9)

Eighty percent of these are preventable as they depend strongly on quality of care. ${ }^{7}$

The three delays increase the risk to a woman's life during pregnancy, delay in deciding to seek care (First delay), delay in reaching a medical facility (Second delay) and delay in receiving quality care at the facility (Third delay). ${ }^{8}$ The first and second delays are directly related to the factors in the family and community while third delay is connected with factors related to health facility and quality of care.

Identification of institutional factors of third delay and their reduction can improve the quality of care at existing medical facilities. This will have a greatest impact in reducing maternal deaths.

Faridpur Medical College Hospital, a 250 bedded hospital, is a tertiary public health care centre in Bangladesh situated in Faridpur district. In addition to provide clinical service this hospital is providing training to undergraduate medical students and 
postgraduate medical specialists including Obstetricians and Gynecologists. The aim of this study is to determine the magnitude of maternal mortality in this institution and to identify the institutional factors causing the third delay and thereby contributed significantly to maternal death.

\section{Methods and Materials:}

This is a cross-sectional study. During the study period analysis of maternal deaths were done at the end of each month. Information was collected from case records and from attending nurses, doctors, consultants and sometimes from relatives of the patients when available. Information was collected regarding number and causes of maternal deaths and various factors causing delay in the proper management of these patients. All collected information was recorded.

Blood transfusion was regarded delayed when it could not be transfused within 2 hours of necessity. Attendance by senior doctors is considered delayed when it was not possible within 2 hours of patient's admission or of development of emergency in admitted patients. Operative interventions were regarded delayed when it could not be done within 2 hours of necessity. Eclamptic patients with complications, patients with septic shock, heart failure, and anesthetic complications were regarded to need ICU facility. Non availability of medicines was regarded as a contributing factor when the specific drugs for the disease that cause maternal death were unavailable, as for example Inj. $\mathrm{MgSO}_{4}$ in case of eclampsia or oxytocic drugs in case of postpartum hemorrhage.

Limitations of the study: Data regarding total number deliveries were collected from record book which may not be strictly accurate. Some contributing factors may be missed because of lack of information. Maternal mortality is expressed as total number of maternal death per 100,000 of deliveries instead of live birth and case fatality ratio is not expressed.

\section{Results}

Table-I shows the distribution of maternal death by year. During the period of January 2001 to December
2005 there were total 10432 deliveries and 202 maternal deaths recorded giving the overall maternal death of 2010.5/100,000 total deliveries.

Table-I

\begin{tabular}{cccc} 
Maternal mortality per 100,000 of total deliveries \\
Year & $\begin{array}{c}\text { No. of } \\
\text { deliveries }\end{array}$ & $\begin{array}{c}\text { Maternal } \\
\text { death }\end{array}$ & $\begin{array}{c}\text { Maternal death } \\
\text { per 100,000 }\end{array}$ \\
\hline 2001 & 1519 & 17 & $1119.2 / 100,000$ \\
2002 & 1520 & 49 & $3223.7 / 100,000$ \\
2003 & 1758 & 41 & $2337.5 / 100,000$ \\
2004 & 2896 & 49 & $1692.6 / 100000$ \\
2005 & 2739 & 46 & $1679.5 / 100000$ \\
\hline Total & 10432 & 202 & $2010.5 / 100000$ \\
\hline
\end{tabular}

Table-II shows the causes of maternal death. The main causes are eclampsia (36\%), hemorrhage (27\%), ruptured uterus (10\%), sepsis $(9 \%)$ and induced abortion $(7 \%)$.

\section{Table-II}

Causes of maternal death

Causes of maternal death Number Percentage

1. Eclampsia $72 \quad 36 \%$

2. Hemorrhage $55 \quad 27 \%$

3. Ruptured uterus $\quad 20 \quad 10 \%$

4. Sepsis $18 \quad 9 \%$

5 Induced abortion $\quad 14 \quad 7 \%$

6. Obstructed labor $\quad 04 \quad 2 \%$

7. Jaundice $07 \quad 3 . \%$

8. Anemia $04 \quad 2 \%$

9. Heart disease $\quad 04 \quad 2 \%$

10.Death due to anesthetic $\quad 04 \quad 2 \%$ complication

\begin{tabular}{lll}
\hline Total & 202 & 100 \\
\hline
\end{tabular}

The identified institutional factors contributing to maternal death are shown in table-III. Contributing factors were identified in $130(64.4 \%)$ cases of maternal death. In many cases more than one factor were present. Delayed or failed blood transfusion was 


\section{Table-III}

\section{Institutional factors contributing to maternal death}

(Total no of death n- 202)

\begin{tabular}{lcc} 
Factors & Number & Percentage \\
\hline Delayed or failed blood transfusion & 81 & $40 \%$ \\
Operative interventions were delayed or not possible & 75 & $37 \%$ \\
Delayed or non attendance by senior doctors & 50 & $24.8 \%$ \\
Non availability of ICU( Intensive care unit) facility & 60 & $29.7 \%$ \\
Operations done by junior doctors without supervision & 20 & $9.9 \%$ \\
Non availability of drugs & 15 & $7.4 \%$ \\
\hline
\end{tabular}

most common contributing factor which was identified in $81(40 \%)$ cases. Other factors weredelayed or lack of operative interventions in $75(37 \%)$ cases; delayed or nonattendance by senior doctors in $50(24.8 \%)$ cases; non availability of ICU in 60 (29.7\%) cases; operations done by junior doctors without supervision in $20(9.9 \%)$ cases and non availability of drugs in $15(7.4 \%)$ cases.

\section{Discussion}

This study shows very high maternal mortality in Faridpur Medical College Hospital which was $2010.5 / 100,000$. This is a hospital based study done in one hospital only and does not reflect exact situation in the community and therefore maternal mortality of this study is not comparable with those estimated by other organization such as Centre for Health and Population Research ICDDR,B, National Institute of Population Research and Training, Bangladesh Bureau of Statistics, which were much less than that of the present study. $9,10,11$

But it is also higher in comparison with that of other studies in other tertiary health centre of our country. ${ }^{12,13,14}$

Being a tertiary health care centre, this high rate is not acceptable. The poor socioeconomic condition of the people of this area, delayed referral/transfer of the patient to the hospital and the deficient health infrastructure of this hospital may play a part to this high rate.

The causes of maternal mortality in this study are same as in other studies of our country which are eclampsia, hemorrhage, sepsis, ruptured uterus, induced abortion, and obstructed labor etc. ${ }^{3,}$ 4, 5, 6, 12, 13,14

Different studies abroad also show the similar causes of maternal mortality. ${ }^{15,16,17,18,19}$

In $64.4 \%$ cases of present study one or more contributing factors for maternal death were present. Substandard care factors were identified in majority of maternal death in several studies. ${ }^{15,20,21,22}$

The most common factor was related to blood transfusion in present study which is consistent with other studies. ${ }^{15,20}$

The other factors such as delayed lack of operative interventions, delayed or nonattendance by senior doctors, operative interventions by junior doctors and lack of ICU facility and regular supply of emergency drugs were also identified in other studies. But the incidence varies from place to place. ${ }^{15,20,21,22}$

The causes blood transfusion related problem at the study place were: insufficient manpower to run the blood bank 24 hours a day; blood was not available in blood bank; as our people do not willingly donate blood and patients had to buy blood from professional donor; sometimes patients could not afford blood and the service charge. The causes of nonattendance by senior doctors and delayed operative interventions were: there were no established posts for resident surgeon and registrar in the department of Obstetrics and Gynecology of this hospital; insufficient manpower (many established posts of obstetricians 
and anesthetists remained vacant); senior doctors lived far from the hospital; nonfunctioning of telecom system; nonfunctioning of ambulance; private practice of obstetricians and anesthetists; negative attitude and lack of responsibilities of both junior and senior doctors.

Other factors were lack ICU facility and absence of regular supply of emergency lifesaving medicines in this hospital and poor patients could not bought the medicine from outside. Absence of these facilities makes the management of critically ill patient difficult and increases the incidence of maternal death.

This is the scenario of public health services in many places of our country.

Globally an annual decline of $5.5 \%$ in maternal mortality ratio is required to achieve MDG 5, which aims to reduce the maternal death by $75 \%$ by 2015 . But the maternal mortality ratio has decreased at an average of less than $1 \%$ annually between 1990 and 2005. ${ }^{1}$

To achieve MDG 5, improving health care for women and providing universal access to reproductive health services must be prioritized. This includes access to family planning, prevention of unplanned pregnancies and provision of high-quality pregnancy and delivery care, including emergency obstetric care.

Improving the health care system is undoubtedly a critical component to reduce maternal morality. One of the most effective methods of bringing about health changes is for governments to prioritize them. Political commitment is vital to the success of various programs for reduction of maternal death. ${ }^{23}$

Countries such as Bolivia, Brazil China, Egypt, Morocco and Peru have made good progress toward achieving MDG-5. 24

This become possible as successful programmes are being implemented by their government.

Bangladesh has one of the highest rates of maternal mortality in the world, and despite substantial advances over the last two decades, it remains comparatively high. A simple extrapolation of recent trends indicates that this MDG will not likely to be met. One of the most significant impediments to better maternal health outcomes is the current state of public health services. ${ }^{25}$

The present study shows the present status of one of the tertiary public health centre in our country.

\section{Conclusion:}

Improvement of infrastructure of health centre by implementation of successful programme can provide high quality emergency obstetric care services. This is an essential element of strategies to reduce the maternal mortality in our country.

\section{References:}

1. Maternal Mortality in 2005. Estimates developed by WHO, UNICEF, UNFPA, and The World Bank. 2007.

2. Khan KS, Wojdyla, Say L, Gulmezoqlu AM, Van Look PF. WHO analysis of causes of maternal death: a systematic review. Lancet 2006; 367(9516):1066-74.

3. Fauveau V, Koenig MA, Chakrabarty, et al. Causes of maternal mortality in rural Bangladesh, 1976-85. Bull World Health Organ. 1988; 66: 643-51.

4. Khan AR, Jahan FA, Begum SF. Maternal mortality in rural Bangladesh: the Jamalpur Distric. Stud Fam Plann. 1988 Jan-Feb; 17(1):7-12.

5. Akhter HA, Situation analysis of maternal health in Bangladesh. Paper presented at National Conference on Safe Motherhood, Dhaka, December 1994.

6. Rahman F, Whittaker M, Hossain MB. Maternal mortality in rural Bangladesh, 1982-1990: data from verbal autopsies. Dhaka: MCH-FP Extension Project, ICDDR, B, 1993. (Working paper no. 81).

7. de Bernis L d, Dumont A, Bouillin D, Gueye A, Dompnier JP, Bouvier-Colle MH. Maternal morbidity and mortality in two different populations of Senegal: a prospective study (MOMA survey). Br J Obstet Gynecol 2000; 107: 68-74.

8. Rai N K, Dali S M. Making pregnancies safer in South-East Asia. Regional Health Forum WHO South-East Asia Region 2002 (Volume 6, No.1)

9. Mahbub-ul-Alam, Kabir H, Nowsheruddin AH, Sirajuddin AKM, Ashraf A. assessment of yearly geographical reconnaissance of the Bangladesh health and population sector programme. Dhaka: ICDDR,B: Centre for Health and Population Research, 2001:28-31. (ICDDR,B working paper no.149.)

10. National Institute of Population Research and Training. Bangladesh maternal health services and maternal mortality survey 2001. Dhaka: National Institute of Population Research and Training, 2003. $234 \mathrm{p}$.

11. Bangladesh Bureau of Statistics. Report of sample vital registration system 2002. Dhaka: Bangladesh Bureau of Statistics, 2004. 291 p. 
12. S Tasnim et all. Maternal Death Audit: Experience from a Periurban Hospital. J Bangladesh Coll Phys Surg 2006; 24 $5-9$.

13. Sayeba A. Presentation of workshop on facility based maternal death review at Dhaka Medical College Hospital, 2005, Dhaka.

14. Begum N. Maternal mortality in Mymenshing Medical College Hospital: 1984-1988. Bangladesh J Obs Gynecol 1991;6: 14-21.

15. Shah N, Khan NH. Third delay of maternal mortality in a tertiary hospital. Rawl Med J 2007;32: 163-167.

16. Jafarey SN Maternal Mortaliy in Pakistan- compilation of available data. J Pak Med Assoc. 2002;52:539-44.

17. Onah HE, Okaro MJ, Umeh U, Chigbu CO. Maternal Mortality in health institutions with emergency obstetric care $\mathrm{f}$ acilities in Enugo State, Nigeria. J Obstet Gynecol 2005;25:569-74

18. Uzoigwe SA, John CT. Maternal Mortality in the University of Port Harcourt Teaching Hospital, Port Harcourt in the last year before the new millennium. Niger J Med. 2004;13: 32-5.

19. Thonneau F, Matsudai T, Alihonou E et al. Distribution of causes of maternal mortality during delivery and postpartum: results of an African multicentre hospital-based study. Eur J Obstet Gynecol Reprod Biol. 2004;114:150-4.

20. EJ Udoma et al. The role of institutional factors in maternal mortality from obstructed labour. Global J Med Sci. 2003; 2(1): 13-17.

21. Samuel, Hailu. Delays in Maternal Morbidity and Mortality at facility level. Retrieved November 07, 2009 from http://hdl.handle.net/123456789/993.

22. Friday E. et al. Maternal Mortality in Ile-Ife,Nigeria: A Study of Risk factors. Studies in Family Planning 1992;23(5): 319-324.

23. Nawal M. Nour. An Introduction to Maternal Mortality. Rey Obstet Gynecol. 2008; 1(2): 77-81.

24. The United Nations Children's Fund (UNICEF). Countdown to 2015: Maternal, Newborn and Child Survival. Executive summery: Tracking Progress in Maternal, Newborn and Child Survival. The 2008 report. New York: UNICEF; 2008.

25. To the MDGs and Beyond: Accountability and Institutional Innovation in Bangladesh. Bangladesh Development series. Paper No: 14. The World Bank Office. Dhaka. January 2007. 